\title{
Experimental Model of Atelectasis in Newborn Piglets
}

\author{
Talitha Comaru PhD, Humberto Holmer Fiori PhD, Renato Machado Fiori PhD, \\ Priscila Padoim MSc, Jaqueline Basso Stivanin MSc, and Vinicius Duval da Silva PhD
}

\begin{abstract}
BACKGROUND: There are few studies using animal models in chest physical therapy. However, there are no models to assess these effects in newborns. This study aimed to develop a model of obstructive atelectasis induced by artificial mucus injection in the lungs of newborn piglets, for the study of neonatal physiotherapy. METHODS: Thirteen newborn piglets received artificial mucus injection via the endotracheal tube. $X$-rays and blood gas analysis confirmed the atelectasis. RESULTS: The model showed consistent results between oxygenation parameters and radiological findings. Ten $(\mathbf{7 6 . 9 \%})$ of the 13 piglets responded to the intervention. This did not significantly differ from the expected percentage of $50 \%$ by the binomial test $(95 \%$ CI $46.2-95 \%, P=.09)$. CONCLUSIONS: Our model of atelectasis in newborn piglets is both feasible and appropriate to evaluate the impact of physical therapies on atelectasis in newborns. Key-words: atelectasis; animal model; mechanical ventilation; newborn; mucus; physiotherapy; swine. [Respir Care 2014;59(1):121126. (C) 2014 Daedalus Enterprises]
\end{abstract}

\section{Introduction}

There are increasing concerns over the safety of some forms of chest physiotherapy used in newborn infants. ${ }^{1,2}$ Although some experimental studies are designed to evaluate infant diseases, there are currently no models proven capable of accurately assessing these effects in newborns.

Researchers in Canada have studied the effects of a series of manual physical therapy techniques in anesthetized and paralyzed dogs without lung injury. ${ }^{3}$ A study

Dr Comaru, Ms Padoim, and Ms Basso Stivanin are affiliated with the Postgraduate Program in Medicine-Pediatrics and Child Health; Drs Holmer Fiori and Machado Fiori are affiliated with the Department of Pediatrics; and Dr Duval da Silva is affiliated with the Department of Pathology, Pontifícia Universidade Católica do Rio Grande do Sul, Porto Alegre, Rio Grande do Sul, Brazil.

The authors have disclosed no conflicts of interest.

Dr Comaru presented a version of this paper at the European Respiratory Society Congress 2012, held September 1-5, 2012, in Vienna, Austria.

Correspondence: Renato Machado Fiori PhD, Postgraduate Program in Medicine-Pediatrics and Child Health, Pontificia Universidade Católica do Rio Grande do Sul, Avenida Ipiranga 6690, Porto Alegre, Rio Grande do Sul, 90610-000 Brazil. E-mail: fiori@ pucrs.br.

DOI: $10.4187 /$ respcare. 02352 group in Australia used a healthy adult sheep model to evaluate variability in the performance of manual physical therapy by physiotherapists. ${ }^{4,5}$ Adult rabbits were used as an experimental model in Japan, in studies of the effectiveness of rib cage compression in removing secretions and improving the resolution of obstructive atelectasis, $, 6,7$ and the effectiveness of physical therapy techniques in removing secretions from the trachea, using a meconium aspiration syndrome model. ${ }^{8}$ Brazilian researchers proposed a model that mimics respiratory physiotherapy in Wistar rats. ${ }^{9}$ In those studies the findings were inconclusive as to the effectiveness of chest physiotherapy techniques, but they represent an advance over previous approaches for the preparation and use of animal models in this field.

Ventilated adult pigs have been successfully used as an experimental model of respiratory disease, ${ }^{10-12}$ and newborn pigs as a model of meconium aspiration syndrome. ${ }^{13-16}$ Additionally, studies on artificial mucus injection have been proposed to evaluate mucus transport, using artificial polymers with properties similar to those of human mucus. ${ }^{17,18}$ Given the characteristics of newborn piglets, ${ }^{19}$ these animals appear to be a promising model for the evaluation of respiratory interventions in newborns cared for in neonatal ICUs, and a pilot study investigated the feasibility of this animal model. ${ }^{20}$ The objective of the present study was to ascertain whether newborn piglets 
can be an adequate model of obstructive atelectasis induced by injection of artificial mucus.

\section{Methods}

The study was approved by the Ethics Committee for Animal Experimentation and performed at the Laboratory for Surgical Skills Training and Research of our institution. Animal care complied with the Guide for the Care and Use of Laboratory Animals, published by the United States National Institutes of Health, ${ }^{21}$ and with local government guidelines (law 11,794). ${ }^{22}$

\section{Study Design}

Twenty-one newborn piglets (mean \pm SD weight $1,690 \pm 71 \mathrm{~g}$ at the time of the experiment), derived from a cross between Large White and Landrace pigs, and obtained from a local farm at less than 24 hours of life were used in this study. As it was a new model, 4 animals were used in a pilot study for mucus injection, to quantify how much artificial mucus could produce effective, but not total, atelectasis. These 4 animals received $0.2 \mathrm{~mL} / \mathrm{min}$ of mucus, as previously described. ${ }^{6,7}$ Additionally, 2 animals were subjected to the surgical protocol but were placed on mechanical ventilation for 5 hours without mucus injection, for histopathology analysis. Two other animals were used to test the endotracheal suction model. In these latter 4 animals, no imaging or blood gas analyses were performed. Therefore, as in the pilot study for mucus injection, these animals were not considered in the atelectasis model. Finally, 13 animals were used for the atelectasis model, in 2 phases. Figure 1 illustrates the flow of the study.

All the piglets had free access to the sow from birth, until they were transported by experienced personnel from the farm to the laboratory, where they were housed in a

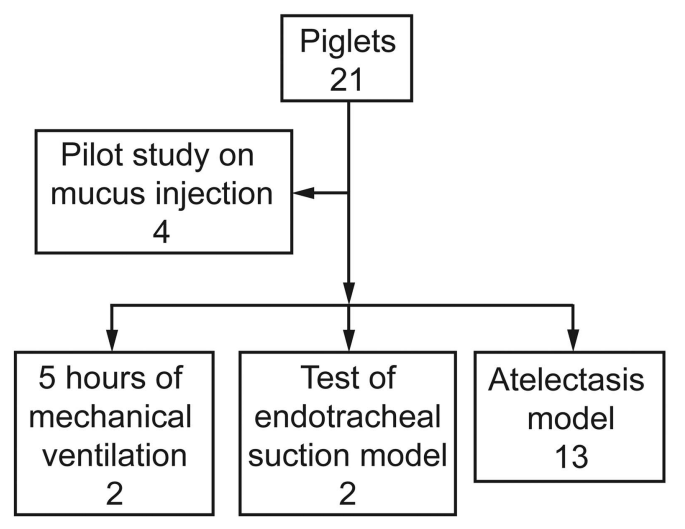

Fig. 1. Flow chart.

\section{QUICK LOOK}

\section{Current knowledge}

Chest physical therapy is frequently ordered in newborns with radiographic signs of atelectasis or secretion retention. The process by which chest physical therapy aids in the resolution of atelectasis and the clinical utility of this procedure are controversial.

\section{What this paper contributes to our knowledge}

A model of atelectasis in newborn piglets was found to be feasible and appropriate for evaluating the impact of physical therapies on atelectasis in human newborns.

heated environment and bottle-fed until the time of the experiment.

\section{Animal Preparation and Measurements}

The piglets were placed in the supine position and kept at $38-39^{\circ} \mathrm{C}$, using a heating blanket. General anesthesia was induced with ketamine $(5 \mathrm{mg} / \mathrm{kg})$ and midazolam $(0.5 \mathrm{mg} / \mathrm{kg})$, and a 5 -French umbilical catheter was inserted into the umbilical vein and artery for medication administration and blood gas analysis. A tracheostomy was performed and an uncuffed endotracheal tube (ETT) was inserted. After gaining access to the airway, the piglets were paralyzed with pancuronium and ventilated mechanically with a time-cycled, pressure-controlled ventilator (BP 200, Pró-Médico, Rio de Janeiro, Brazil), with a breathing frequency of 40 breaths $/ \mathrm{min}$, peak inspiratory pressure of $15 \mathrm{~cm} \mathrm{H}_{2} \mathrm{O}$, PEEP of $5 \mathrm{~cm} \mathrm{H}_{2} \mathrm{O}$, and $\mathrm{F}_{\mathrm{IO}_{2}}$ of 1.0. Ketamine $(5 \mathrm{mg} / \mathrm{kg})$, fentanyl $(5 \mu \mathrm{g} / \mathrm{kg})$, midazolam $(0.5 \mathrm{mg} / \mathrm{kg})$, and pancuronium $(0.1 \mathrm{mg} / \mathrm{kg})$ were administered every 1-2 hours during the procedure, or when deemed necessary, to keep the animals anesthetized and paralyzed. Heart rate and oxygen saturation were measured continuously, via pulse oximetry (Datex-Ohmeda, Louisville, Colorado).

After preparation, the animals were placed in the right lateral decubitus position, with the head elevated to $30^{\circ}$, and maintained in this position until the end of the experiment. This position was chosen to facilitate mucus injection and deposition, preferably in the right lung.

\section{Artificial Mucus}

The artificial mucus was prepared with $1 \mathrm{~g}$ of polyethylene oxide, with a molecular weight of 5,000,000 (SigmaAldrich, St Louis, Missouri), diluted to $100 \mathrm{~mL}$ with distilled water, placed on a mechanical shaker (model 711, 
Fisatom, São Paulo, Brazil), and cooled in an ice bath at $-20^{\circ} \mathrm{C}$ (model 116-R, Fanem, São Paulo, Brazil). After solubilization, $1 \%$ xylene cyanol (Sigma-Aldrich, St Louis, Missouri) was added to the solution. The rheological properties of the artificial mucus were analyzed using a magnetic rheometer (AR 1500 ex, TA Instruments, New Castle, Delaware), and the values were: elastic modulus $\left(\mathrm{G}^{\prime}\right)$ 58 Pascals, viscous modulus (G") 78 Pascals, at a frequency of $1.0 \mathrm{rad} / \mathrm{s}$. The homogeneity of the artificial mucus throughout the study was measured using a rotational viscometer (VP 1000, Viscotech, Tarragona, Spain). A viscosity of $860 \mathrm{mPascals}$ was observed in all samples, using the spindle R3.

\section{Atelectasis Model}

The artificial mucus model was modified based on descriptions from other authors in studies with animal models, ${ }^{6,7}$ and the results of our pilot study of mucus injection. Briefly, an injection system was created by placing a Y-connector between the ETT and the ventilator circuit. A 6-French catheter (measured to ensure that its tip would be $1 \mathrm{~cm}$ below the ETT tip) was connected to a syringe infusion pump (model ST670T, Samtronic, São Paulo, Brazil) and introduced into the ETT, and the artificial mucus was administered at $0.6-0.8 \mathrm{~mL} / \mathrm{kg}$. The animals were maintained under artificial ventilation for $30 \mathrm{~min}$ after administration of the mucus, as in previous studies. ${ }^{6,7}$

\section{Radiological Analysis}

An anteroposterior chest radiograph was obtained $30 \mathrm{~min}$ after the artificial mucus was infused, to evaluate the effectiveness of the atelectasis model. The radiographs were later analyzed by 2 pediatric radiologists not involved in the study. The scores used for evidence of atelectasis, mediastinal shift, and hyperinflation were adapted for use in animals from a previous study. ${ }^{23}$ The presence or absence of hyperinflation and/or a mediastinal shift was scored as $0=$ absence, and $1=$ presence. Atelectatic areas were quantified using a modified chest radiograph scoring system ${ }^{23}$ : $0=$ no atelectasis, $1=$ partial atelectasis (each lobe), 2 = total atelectasis (each lobe). For analysis the animals were divided into 2 groups for the presence or absence of atelectasis: responders $=$ radiographic evidence of atelectasis, non-responders $=$ no radiographic evidence of atelectasis.

\section{Blood Gas Analysis}

Blood gas analysis was planned before and $30 \mathrm{~min}$ after mucus injection in all animals, to evaluate oxygenation. However, as 2 of the first 4 animals had not developed radiographic atelectasis or a $>40 \%$ drop in $\mathrm{P}_{\mathrm{aO}_{2}}$ from baseline at $30 \mathrm{~min}$ after mucus injection, we decided to include a new blood gas analysis immediately after, to determine the need for an additional mucus injection. If an animal did not have a $40 \%$ drop in $\mathrm{P}_{\mathrm{aO}_{2}}$ immediately after mucus injection, $0.5 \mathrm{~mL}$ more artificial mucus was infused in $5 \mathrm{~min}$.

Thus, blood gas analysis was performed before and 30 min after mucus injection in the first 4 animals, and before, immediately after, and $30 \mathrm{~min}$ after in the 9 remaining animals.

\section{Tracheal Suctioning Model}

As described above, 2 animals were randomly selected and used specifically to assess whether the artificial mucus could be adequately suctioned after injection, since other authors have reported difficulty in suctioning of secretions after artificial mucus injection. ${ }^{6}$ The suctioning protocol consisted of infusing $0.2-0.5 \mathrm{~mL}$ of normal saline through the ETT, hyperventilation with manual compression of the bag (6 inflations), and suctioning at a negative pressure of about $50-100 \mathrm{~mm} \mathrm{Hg}$ for 10-15 seconds, using a 6-French gauge catheter. An adapted mucus trap was used to ensure accurate measurement of the suctioned secretions.

\section{Histopathology}

After the experiments the animals were sacrificed via intraventricular injection of $2 \mathrm{~mL}$ of potassium chloride ( $2 \mathrm{~mol} / \mathrm{L}$ ). The lungs of 6 randomly selected animals that received mucus injection, and the 2 animals that underwent the surgery and mechanical ventilation but no mucus injection, were sent for histopathology. In all animals the lungs were inflated with a manual bag, and the trachea was clamped. Then $10 \%$ buffered formalin was injected into the right ventricle and the lungs were excised and fixed in formalin for 24 hours. Histology sections were cut at the base and apex of the right and left lungs. These representative lung samples were paraffin-embedded and serially sectioned at $3 \mu \mathrm{m}$ thickness. After deparaffinization and dehydration the sections were stained with hematoxylin and eosin and analyzed under a biological microscope (Axioskop 40, Zeiss, Oberkochen, Germany).

\section{Statistical Analysis}

Results are expressed as mean $\pm \mathrm{SD}$ or median and $\mathrm{IQR}$, as appropriate. Data analysis was performed via nonparametric methods. The binomial test was used to check whether a difference existed between the $50 \%$ of animals expected to respond to the intervention, the Wilcoxon signed-rank test to indicate the progression of $\mathrm{P}_{\mathrm{aO}_{2}}$ within each animal group, and the Mann-Whitney $U$ test for comparison of the groups of animals. The degree of agreement 


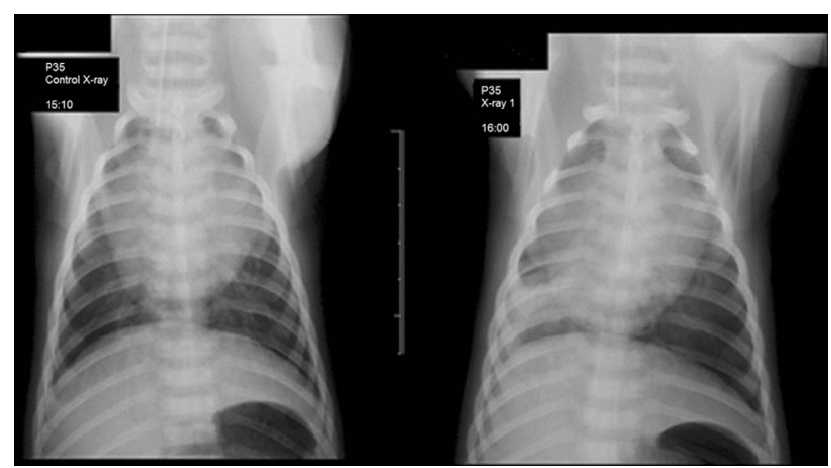

Fig. 2. Radiographs of a newborn piglet before (left) and after (right) injection of artificial mucus, which produced atelectasis in 10 of 13 piglets.

between radiologists was estimated with the kappa coefficient. The level of significance was set at 5\%, and all statistical analyses were performed with statistics software (SPSS 11.0, SPSS, Chicago, Illinois).

\section{Results}

In the pilot study of mucus injection we found a large lung collapse, so those results were not considered in the final analysis, but provided sufficient information to calculate the ideal quantity of mucus to develop the atelectasis model, based on the weight/volume ratio estimated in previous studies. ${ }^{6,7}$

According to radiological evaluation performed $30 \mathrm{~min}$ after artificial mucus injection, atelectasis was present in 10 of 13, of which 1 had complete right lung atelectasis, 3 had atelectasis of 2 or more lobes, and 6 had atelectasis of only one lobe. Except for 2 animals, the radiologists independently agreed on the radiological findings (kappa $=0.80, P=.003)$. In one case of disagreement, one radiologist reported no atelectasis and the other reported right-upper-lobe atelectasis. In the other case, one reported middle-lobe and right-lower-lobe atelectasis and

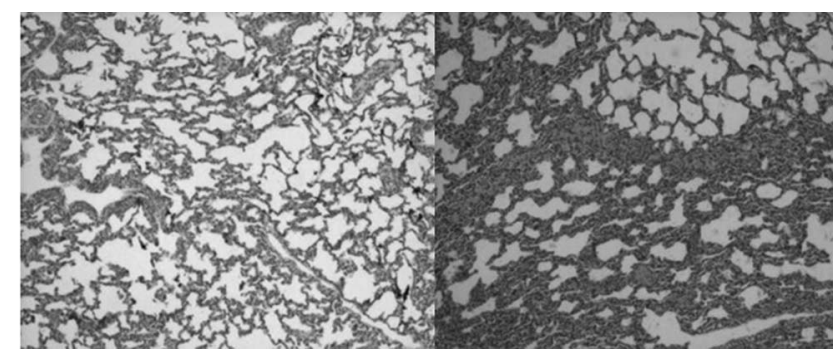

Fig. 4. Histology sections of a representative sample of the lower lobe of a newborn piglet that received only mechanical ventilation (left) and one that received mechanical ventilation and injection of artificial mucus (right). Magnification $50 \times$.

the other reported only right-lower-lobe atelectasis. The degree of atelectasis was described as previously reported. ${ }^{23}$ Mediastinal shift was found in 7, and hyperinflation in 5, of the 13 piglets. Figure 2 illustrates the experimental production of atelectasis.

Ten of the 13 animals (76.9\%) responded to intervention, which did not differ from the expected percentage of $50 \%$ by the binomial test $(95 \%$ CI $46.2-95 \%, P=.09)$. The variation in $\mathrm{P}_{\mathrm{aO}_{2}}$ from before intervention up to $30 \mathrm{~min}$ after injection of artificial mucus was statistically significant in the responders group $(P=.01)$, and not significant in the non-responders group $(P=.29)$. The median $\mathrm{P}_{\mathrm{aO}_{2}}$ before $(P=.47)$ and 30 min after injection of artificial mucus $(P=.08)$ showed no significant differences between groups: $345 \mathrm{~mm} \mathrm{Hg}$ (IQR 282-360 mm Hg) before versus $190.5 \mathrm{~mm} \mathrm{Hg}$ (IQR $172-264 \mathrm{~mm} \mathrm{Hg}$ ) after in the responders group, and $285 \mathrm{~mm} \mathrm{Hg}$ (IQR 254-347 $\mathrm{mm} \mathrm{Hg}$ ) and $369 \mathrm{~mm} \mathrm{Hg}$ (IQR 234-430 mm Hg) in the nonresponders. Figure 3 shows the $\mathrm{P}_{\mathrm{aO}_{2}}$ changes.

Macroscopic examination revealed atelectasis, characterized by reddened areas and compression of the lung parenchyma, in all animals subjected to injection of artificial mucus, regardless of radiographic outcomes, but not in the animals subjected only to mechanical ventilation. Conversely, qualitative histopathology, including the ani-
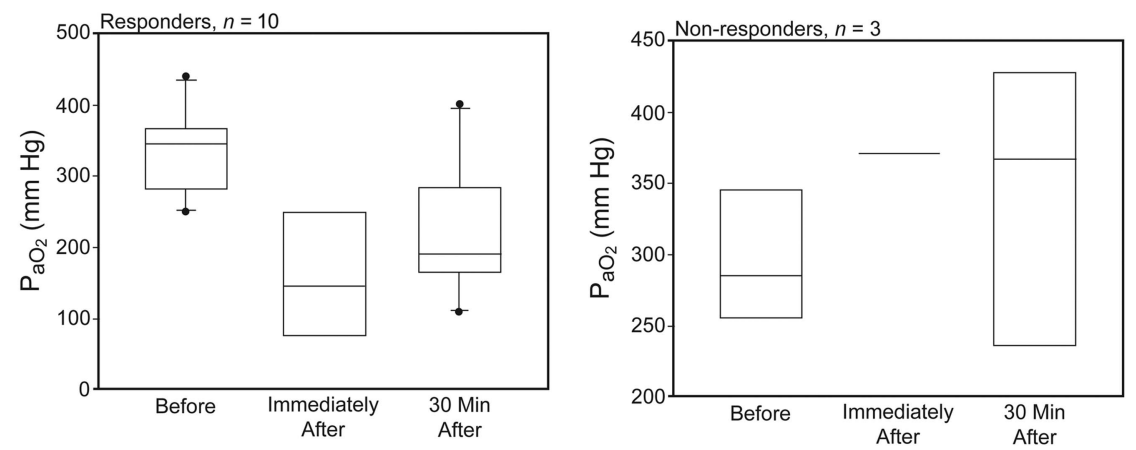

Fig. 3. $\mathrm{P}_{\mathrm{aO}_{2}}$ before, immediately after, and $30 \mathrm{~min}$ after injection of artificial mucus in newborn piglets. Responders $P=.01$, non-responders $P=.29$, via Wilcoxon signed-rank test. In each data bar the horizontal line represents the median, the top and bottom of the bar represent the IQR, the whisker bars represent the 25th and 75th percentiles, and the dots represent outliers. 


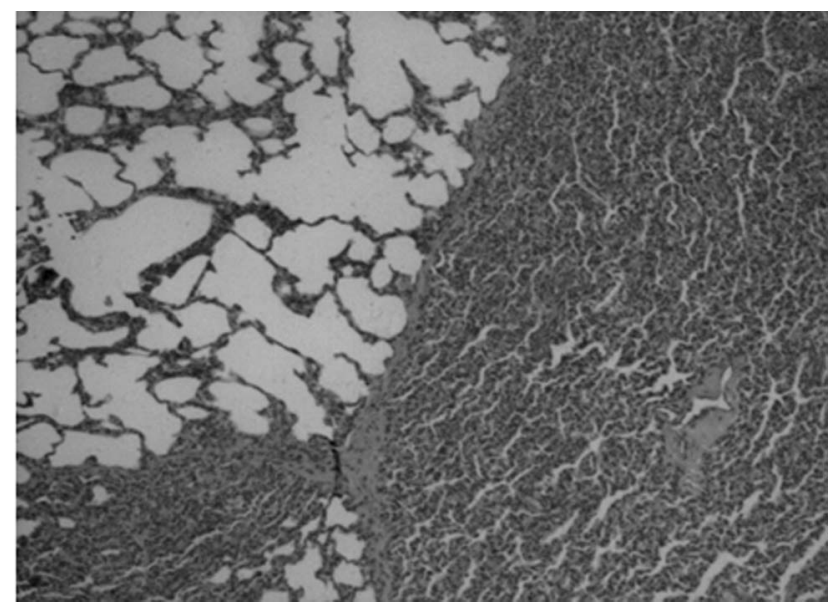

Fig. 5. Histology section of a representative sample of the right lower lobe of a newborn piglet after injection of artificial mucus. Magnification $50 \times$.

mals that did not receive artificial mucus but were ventilated for 5 hours, showed areas of hypoexpansion at the base of the lungs, with reduced alveolar space, and neutrophils and polymorphonuclear cells. The animals that received only mechanical ventilation showed no structural changes in alveolar septae, whereas the animals that received mechanical ventilation and artificial mucus showed deformation of alveolar septae, with loss of normal features (Figs. 4 and 5).

Unlike other authors, who have reported difficulty in suctioning secretions after artificial mucus injection, ${ }^{6}$ our suctioning strategy was successful in both cases, with $0.4 \mathrm{~mL}$ of mucus suctioned from each animal. All animals had heart rate and oxygen saturation within the expected normal ranges during all phases and stages of the study. ${ }^{21}$

\section{Discussion}

Our experimental model is in line with current recommendations for animal-model studies on mucus transport, ${ }^{24,25}$ in which various types of artificial mucus have been used. ${ }^{67,17,18}$ Furthermore, the low viscosity/elasticity ratio and low-frequency measurements we used are characteristic of a more elastic mucus, ${ }^{18}$ which is a suitable model of human infants on mechanical ventilation, in whom buildup of secretions is due mainly to mechanical ventilation.

Although there was a strong association between the decrease in $\mathrm{P}_{\mathrm{aO}_{2}}$ and the radiological findings, the latter remains the parameter of choice for the clinical diagnosis of atelectasis. Unoki et $\mathrm{al},{ }^{6}$ using blood gas analysis as a criterion for the diagnosis of atelectasis, with subsequent pathology confirmation, found different results in oxygenation and changes in the site of atelectasis, which may be explained by the characteristics of the artificial mucus used in the study and by the animal's position during injection. In the study by Zidulka et al, ${ }^{3}$ in which chest physiotherapy techniques were evaluated in previously healthy dogs, reported histology findings characteristic of atelectasis, most prominently in lung regions where physical therapy techniques were applied. Although those findings were not analyzed quantitatively, blood gas analysis showed improved $\mathrm{P}_{\mathrm{aO}_{2}}$ and decreased $\mathrm{P}_{\mathrm{aCO}}$ during chest physiotherapy. A study using rats ${ }^{9}$ evaluated the presence of atelectasis, employing histopathology and morphometric analysis to measure the number of collapsed alveoli, and found no difference between the groups subjected to a model that mimics physiotherapy and the group subjected only to atelectasis. However, blood gas analysis was not performed in that study. Additionally, none of those studies used imaging techniques, which prevents the measurement of the clinical dimension of atelectasis in each case.

In our study the artificial mucus was infused with the animal in the right lateral decubitus position, making it possible to "drive" the atelectasis to the right lung, which occurred in 8 out of 10 animals with radiographic evidence of atelectasis. The qualitative histopathology showed collapsed areas at the base of the lungs of the animals that received only mechanical ventilation, without injection of artificial mucus, as well as of the animals in which atelectasis was successfully produced. These results raise the question of the impact of mechanical ventilation in the model, and point to the need to develop study protocols that include blood gas analysis, $\mathrm{x}$-rays, and histopathology of the techniques during chest physiotherapy.

\section{Limitations}

The first limitation is that we used an $\mathrm{F}_{\mathrm{IO}_{2}}$ of 1.0. Although the effects of hyperoxia on lung tissue are well described in the literature, ${ }^{26}$ the technical conditions available at our facility did not allow us to use lower $\mathrm{F}_{\mathrm{IO}_{2}}$. To minimize this problem, ventilatory support was standardized for all the animals. Also, intermittent injection of $0.9 \% \mathrm{NaCl}$, rather than lactated Ringer's solution, may have negatively affected the outcome of arterial blood gas analysis and even contributed to the occurrence of inflammatory reactions in lung tissue. ${ }^{27}$ Importantly, future investigations could use radiopaque markers in the airways ${ }^{10,11}$ to better evaluate the transport properties of the mucus. Finally, we used only the anteroposterior position for the x-rays, which limited our assessments, especially regarding the confirmation of middle lobe atelectasis. ${ }^{28}$

\section{Conclusions}

Our model of induced atelectasis in newborn piglets is both feasible and appropriate to evaluate the impact of therapies on atelectasis in newborns. 


\section{ACKNOWLEDGMENTS}

We thank Mayara Menezes and Guilherme Eder (undergraduate research scholarship holders), Gilmar Pontes Moreira (laboratory technician), and Rosane Ligabue (technical assistant) for their work in this study.

\section{REFERENCES}

1. Flenady VJ, Gray PH. Chest physiotherapy for preventing morbidity in babies being extubated from mechanical ventilation. Cochrane Database Syst Rev 2002;(2):CD000283.

2. Hough JL, Flenady V, Johnston L, Woodgate PG. Chest physiotherapy for reducing respiratory morbidity in infants requiring ventilatory support. Cochrane Database Syst Rev 2008;(3):CD006445.

3. Zidulka A, Chrome JF, Wight DW, Burnett S, Bonnier L, Fraser R. Clapping or percussion causes atelectasis in dogs and influences gas exchange. J Appl Physiol 1989;66(6):2833-2838.

4. Wong WP, Paratz JD, Wilson K, Burns YR. Hemodynamic and ventilatory effects of manual respiratory physiotherapy techniques of chest clapping, vibration, and shaking in an animal model. J Appl Physiol 2003;95(3):991-998.

5. Anning L, Paratz J, Wong WP, Wilson K. Effect of manual hyperinflation on haemodynamics in an animal model. Physiother Res Int 2003;8(3):155-163.

6. Unoki T, Mizutani T, Toyooka H. Effects of expiratory rib cage compression and/or prone position on oxygenation and ventilation in mechanically ventilated rabbits with induced atelectasis. Respir Care 2003;48(8):754-762.

7. Unoki T, Mizutani T, Toyooka H. Effects of expiratory rib cage compression combined with endotracheal suctioning on gas exchange in mechanically ventilated rabbits with induced atelectasis. Respir Care 2004;49(8):896-901.

8. Zhang E, Hiroma T, Sahashi T, Taki A, Yoda T, Nakamura T. Airway lavage with exogenous surfactant in an animal model of meconium aspiration syndrome. Pediatr Int 2005;47(3):237-241.

9. Lima JGM, Reis LFF, Moura FM, Souza CPV, Walchan EM, Bergmann A. Compressão Manual Torácica em um modelo experimental de atelectasia em ratos Wistar. Fisioterapia em Movimento 2008;21(3):77-82. Article in Portuguese.

10. Luna CM, Baquero S, Gando S, Patron JR, Morato JG, Sibila O, et al. Experimental severe Pseudomonas aeruginosa pneumonia and antibiotic therapy in piglets receiving mechanical ventilation. Chest 2007;132(2):523-531.

11. Luna CM, Sibila O, Agusti C, Torres A. Animal models of ventilator-associated pneumonia. Eur Respir J 2009;33(1):182-188.

12. Marumo CK. Efeitos cardiovasculares das manobras de recrutamento alveolar durante lesão pulmonar aguda por ácido clorídrico: estudo experimental em suínos. São Paulo: Universidade de São Paulo; 2007. Article in Portuguese.

13. Wiswell TE, Peabody SS, Davis JM, Slayter MV, Bent RC, Merritt TA. Surfactant therapy and high-frequency jet ventilation in the management of a piglet model of the meconium aspiration syndrome. Pediatr Res 1994;36(4):494-500.

14. Colvero MO, Fiori HH, Fiori RM, Luz JH, de Paula D, Oppermann $\mathrm{C}$, et al. Bronchoalveolar lavage plus surfactant in a piglet model of meconium aspiration syndrome. Neonatology 2008;93(3):188-192.

15. Dargaville PA, Mills JF, Headley BM, Chan Y, Coleman L, Loughnan PM, et al. Therapeutic lung lavage in the piglet model of meconium aspiration syndrome. Am J Respir Crit Care Med 2003;168(4): 456-463.

16. Jeng MJ, Soong WJ, Lee YS, Chang HL, Shen CM, Wang CH, et al. Effects of therapeutic bronchoalveolar lavage and partial liquid ventilation on meconium-aspirated newborn piglets. Crit Care Med 2006; 34(4): 1099-1105.

17. Kim CS, Abraham WM, Chapman GA, Sackner MA. Influence of two-phase gas-liquid interaction on aerosol deposition in airways. Am Rev Respir Dis 1985;131(4):618-623.

18. Puchelle E, Zahm JM, Duvivier C, Didelon J, Jacquot J, Quemada D. Elasto-thixotropic properties of bronchial mucus and polymer analogs. I. experimental results. Biorheology 1985;22(5):415-423.

19. Ferreira RA, Chiquieri J, Mendonça PP, Melo TV, Cordeiro MD, N. SRTR. Comportamento e parâmetros fisiológicos de leitões nas primeiras 24 horas de vida. Ciência e Agrotecnologia 2007;31(6): 1845-1849. Article in Portuguese.

20. Comaru T, Fiori RM, Fiori HH. The use of piglets as experimental model of chest physiotherapy in newborn babies. Sci Med 2011; 21(1):14-15.

21. Institute of Laboratory Animal Research; Commission on Life Sciences; National Research Council. Guide for the care and use of laboratory animals. Washington, DC: National Academy Press; 1996.

22. Procedimentos para o Uso Científico de Animais, Lei 11.794/08 (2008). Portuguese.

23. Hendriks T, de Hoog M, Lequin MH, Devos AS, Merkus PJ. DNase and atelectasis in non-cystic fibrosis pediatric patients. Crit Care 2005;9(4):R351-R356.

24. Tomkiewicz RP, Albers GM, De Sanctis GT, Ramirez OE, King M, Rubin BK. Species differences in the physical and transport properties of airway secretions. Can J Physiol Pharmacol 1995;73(2): 165-171.

25. Felicetti SA, Wolff RK, Muggenburg BA. Comparison of tracheal mucous transport in rats, guinea pigs, rabbits, and dogs. J Appl Physiol 1981;51(6):1612-1617.

26. Davis JM, Dickerson B, Metlay L, Penney DP. Differential effects of oxygen and barotrauma on lung injury in the neonatal piglet. Pediatr Pulmonol 1991;10(3):157-163.

27. Haddad Neta J, Trapp SM, Sturion DJ. Considerações fisiológicas na fluidoterapia em cães e gatos. Arq Ciên Vet Zool UNIPAR 2005; 8(1):63-70. Article in Portuguese.

28. Müller NL, Silva CIS. Imaging of the chest. Philadelphia: Saunders Elsevier; 2008. 